\title{
Fatigue Life Extension of AA2024 Specimens and Integral Structures by Laser Shock Peening
}

\author{
Nikolai Kashaev ${ }^{1 *}$, Sergey Chupakhin ${ }^{1}$, Volker Ventzke ${ }^{1}$, Manfred Horstmann ${ }^{1}$, Stefan Riekehr ${ }^{1}$, Alessandro Barbini ${ }^{1}$, \\ Jorge. F. dos Santos ${ }^{1}$, Sören Keller ${ }^{1}$, Benjamin Klusemann ${ }^{1,2}$ and Norbert Huber ${ }^{1}$ \\ ${ }^{1}$ Institute of Materials Research, Materials Mechanics, Helmholtz-Zentrum Geesthacht, 21502 Geesthacht, Germany \\ ${ }^{2}$ Institute of Product and Process Innovation, Leuphana University of Lüneburg, 21339 Lüneburg, Germany
}

\begin{abstract}
The goal of the present study is to understand the effects of laser shock peening (LSP)-induced residual stresses on the fatigue crack propagation (FCP) behaviour of the commonly used aircraft aluminium alloy AA2024 in T3 heat treatment condition. LSP treatment was performed using a pulsed $\mathrm{Nd}$ :YAG laser on compact tensile C(T)50-specimens with a thickness of $2.0 \mathrm{~mm}$. LSP-treated specimens reveal a significant retardation of the fatigue crack propagation. The fatigue crack retardation effect can be correlated with the compressive residual stresses introduced by LSP throughout the entire specimen thickness. A possible application of the LSP process on a component like panel with three welded stringers representing a part of a fuselage structure was performed as well. The skin-stringer AA2024-AA7050 Tjoints were realised through stationary shoulder friction stir welding (SSFSW), a variant of the conventional friction stir welding process. In this relatively new process, the shoulder does not rotate and therefore does not contribute to the heat generation. Consequently, a reduced and more homogeneous heat input leads to a less affected microstructure and better mechanical properties. The efficiency of the LSP process has been demonstrated resulting in an increase of $200-400 \%$ in fatigue lifetime.
\end{abstract}

\section{Introduction}

Laser shock peening (LSP) is a very promising technique for introducing deep compressive residual stresses in metallic materials [1-2]. The LSP process is essentially based on high-energy pulsed laser beams, which cause the propagation of shock waves in materials or components, and thereby of near-surface compressive residual stresses and work hardening [3-4]. LSP-induced residual stresses can be used to improve the damage tolerance behaviour of lightweight metallic structures. Several researches investigated the effects of LSP on the initiation and propagation of fatigue cracks in aluminium alloy specimens with various notch geometries [1,5-9]. The results clearly demonstrated that LSP can be used as an effective surface treatment technique for reducing or suppressing fatigue crack growth in aluminium alloys. However, application of a not optimised LSP process can produce high surface roughness without introducing noticeable compressive residual stresses [10]. In this case, LSP can reduce the fatigue life of critical components and structures. Therefore, much of the LSP process and its effect remain to be figured out as how the LSP process can be applied in an appropriate way.

The aim of the present study is to understand the effects of LSP-induced residual stresses on the fatigue crack propagation (FCP) behaviour of the commonly used aircraft aluminium alloy AA2024 in T3 heat treatment condition. Furthermore, a possible application of the LSP process is demonstrated on a component like panel with three welded stringers representing a part of a fuselage structure showing the application of LSP to large aircraft structures.

\section{Experimental methods}

\subsection{Material, LSP treatment and SSFSW process}

A $2.0 \mathrm{~mm}$ thick sheet of the aluminium alloy AA2024T3 was used in this study. LSP treatment was performed using a Q-switched Nd:YAG laser operating at $10 \mathrm{~Hz}$ with a wave length of $1064 \mathrm{~nm}$, pulse duration of $10 \mathrm{~ns}$ in case of $\mathrm{C}(\mathrm{T})$-specimens and $20 \mathrm{~ns}$ in case of $\mathrm{M}(\mathrm{T})$ panels. Two different diffractive optics were used to deliver the laser energy in a square spot of $1 \mathrm{~mm} \times 1 \mathrm{~mm}$ and $3 \mathrm{~mm} \times 3 \mathrm{~mm}$ on the specimen surface. In case of the diffractive optic of $3 \mathrm{~mm} \times 3 \mathrm{~mm}$, the specimen surface was covered with an aluminium foil. The LSP treatment was applied on the both surfaces of $\mathrm{C}(\mathrm{T}) 50$ specimens (width $50 \mathrm{~mm}$ ). The initial crack length, $\mathrm{a}_{0}$ was $15 \mathrm{~mm}$ for the LSP-treated specimens using the diffractive optic $1 \mathrm{~mm} \times 1 \mathrm{~mm}$ and $10 \mathrm{~mm}$ for the LSPtreated specimens using the diffractive optic $3 \mathrm{~mm} x$ $3 \mathrm{~mm}$. The treated specimen area was $5 \mathrm{~mm} \times 5 \mathrm{~mm}$ and $15 \mathrm{~mm} \times 15 \mathrm{~mm}$ in case of the diffractive optics $1 \mathrm{~mm} \times$ $1 \mathrm{~mm}$ and $3 \mathrm{~mm} \times 3 \mathrm{~mm}$, respectively. The sequence of LSP spots is depicted in Figure 1. The LSP treatment

Corresponding author: nikolai.kashaev@hzg.de 
was applied up to 5 times ( $5 \mathrm{x}$ overlapping) at the same location. The distance between the area of the LSP patterns and the initial crack tip was $-1 \mathrm{~mm}$ and $-2 \mathrm{~mm}$ for specimens treated using $1 \mathrm{~mm} \times 1 \mathrm{~mm}$ and $3 \mathrm{~mm} \times$ $3 \mathrm{~mm}$ diffractive optics, respectively (crack tip was in the area of the LSP patterns). The LSP-treatments for the $\mathrm{C}(\mathrm{T}) 50$-specimens investigated in this study are summarized in Table 1. The LSP-treatment sequences were also investigated in the previous studies of the authors [15-16].

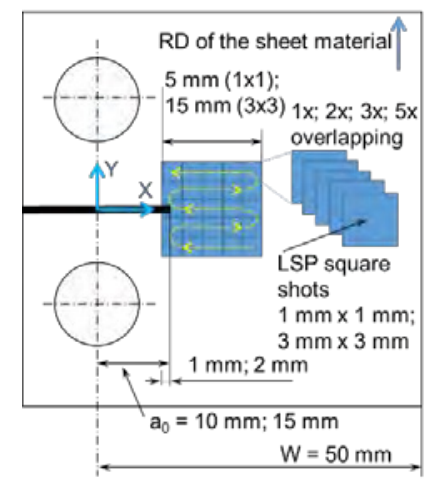

Fig. 1. Geometry of the $C(T) 50$-specimen with positioning of the LSP patterns according to previous studies of the authors [15-16].

A possible application of the LSP process was also demonstrated on a component like panel. The skinstringers T-joints were realised through stationary shoulder friction stir welding (SSFSW), a variant of the conventional friction stir welding (FSW) process. In this variant of the standard FSW process, the shoulder does not rotate, reducing significantly the heat generated and the area affected by the process. This lead to a considerable improvement of the mechanical properties in both static and fatigue tests when compared with FSW. Additionally, a smooth surface is created at the weld crown that does not require any post processing. To produce the T-joint, a design solution as shown in Figure 2(a) was used. The photo and macrograph of the stationary shoulder friction stir welded AA2024AA7050 T-joint are shown in Figure 2(b-c). For details regarding the joining process, the reader is referred to [11].

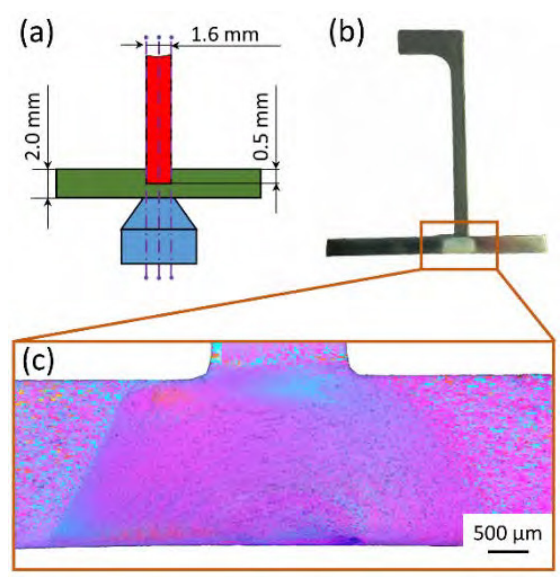

Fig. 2. (a) Sketch of the T-joint in two parts with partial penetration, (b) photo of the T-joint and (c) macrograph of the stationary shoulder friction stir welded skin-stringer T-joint configuration consisting of one skin sheet AA2024-T3 and one stringer AA7050-T7651 welded in one operation.

The LSP treatments on the stationary shoulder friction stir welded three-stringer panels were applied only on one side (stringer-side) using two different strategies (Figure 3 and Table 1).

Table 1. Specimen documentation.

\begin{tabular}{|c|c|c|}
\hline $\begin{array}{c}\text { Specimen } \\
\text { identification }\end{array}$ & $\begin{array}{l}\text { Number of } \\
\text { LSP overlap }\end{array}$ & $\begin{array}{c}\text { Distance of LSP } \\
\text { patterns in front } \\
\text { of the crack tip } \\
{[\mathrm{mm}]}\end{array}$ \\
\hline $\mathrm{BM}$ & - & - \\
\hline LSP $1.3 \mathrm{~J} 1 \mathrm{x} 11 \mathrm{x}$ & 1 & $\begin{array}{l}-1(\text { crack tip in LSP } \\
\left.\text { area, } a_{0}=15 \mathrm{~mm}\right)\end{array}$ \\
\hline LSP $1.3 \mathrm{~J} 1 \mathrm{x} 12 \mathrm{x}$ & 2 & $\begin{array}{l}-1 \text { (crack tip in LSP } \\
\text { area, } a_{0}=15 \mathrm{~mm} \text { ) }\end{array}$ \\
\hline LSP $3 J 1 x 11 x$ & 1 & $\begin{array}{l}-1 \text { (crack tip in LSP } \\
\left.\text { area, } a_{0}=15 \mathrm{~mm}\right)\end{array}$ \\
\hline LSP $3 J 3 x 33 x$ & 3 & $\begin{array}{l}-2(\text { crack tip in LSP } \\
\left.\text { area, } a_{0}=10 \mathrm{~mm}\right)\end{array}$ \\
\hline LSP $3 J 3 x 35 x$ & 5 & $\begin{array}{l}-2(\text { crack tip in LSP } \\
\left.\text { area, } a_{0}=10 \mathrm{~mm}\right)\end{array}$ \\
\hline SSFSW & - & - \\
\hline $\begin{array}{l}\text { SSFSW-LSP1 } \\
(5 \mathrm{~J}, 1 \mathrm{x} 13 \mathrm{x})\end{array}$ & 3 & $4\left(a_{0}=3 \mathrm{~mm}\right)$ \\
\hline $\begin{array}{l}\text { SSFSW-LSP2 } \\
(5 \mathrm{~J}, 3 \times 33 \mathrm{x})\end{array}$ & 3 & $4\left(a_{0}=3 \mathrm{~mm}\right)$ \\
\hline
\end{tabular}

\section{Results and discussion}

\subsection{Residual stress analysis}

For the determination of depth resolved residual stresses, the hole drilling equipment "Prism" was used. "Prism" is equipped with an optical electronic speckle pattern interferometer (ESPI) system that provides high-quality full-field data for accurate residual stress determination. The technique is described in details in [12].

Figure 4 shows the residual stress measurement results obtained using the hole drilling technique. The measurements were performed at three positions in the middle of the LSP-area. Using the tool diameter of $2.0 \mathrm{~mm}$, it was possible to obtain residual stress profiles up to half of the specimen depth $(1 \mathrm{~mm})$. BM specimen shows a non-uniform depth-resolved residual stress profile, where the residual stresses $\sigma_{\mathrm{yy}}$ are slightly higher than the residual stresses in $\mathrm{x}$-direction (direction of crack propagation), $\sigma_{\mathrm{xx}}$. Surface regions show tensile stresses that are compensated through compressive residual stresses in the core region of the specimen. This residual stress state can be caused through the production (rolling) process of the initial sheet material. 


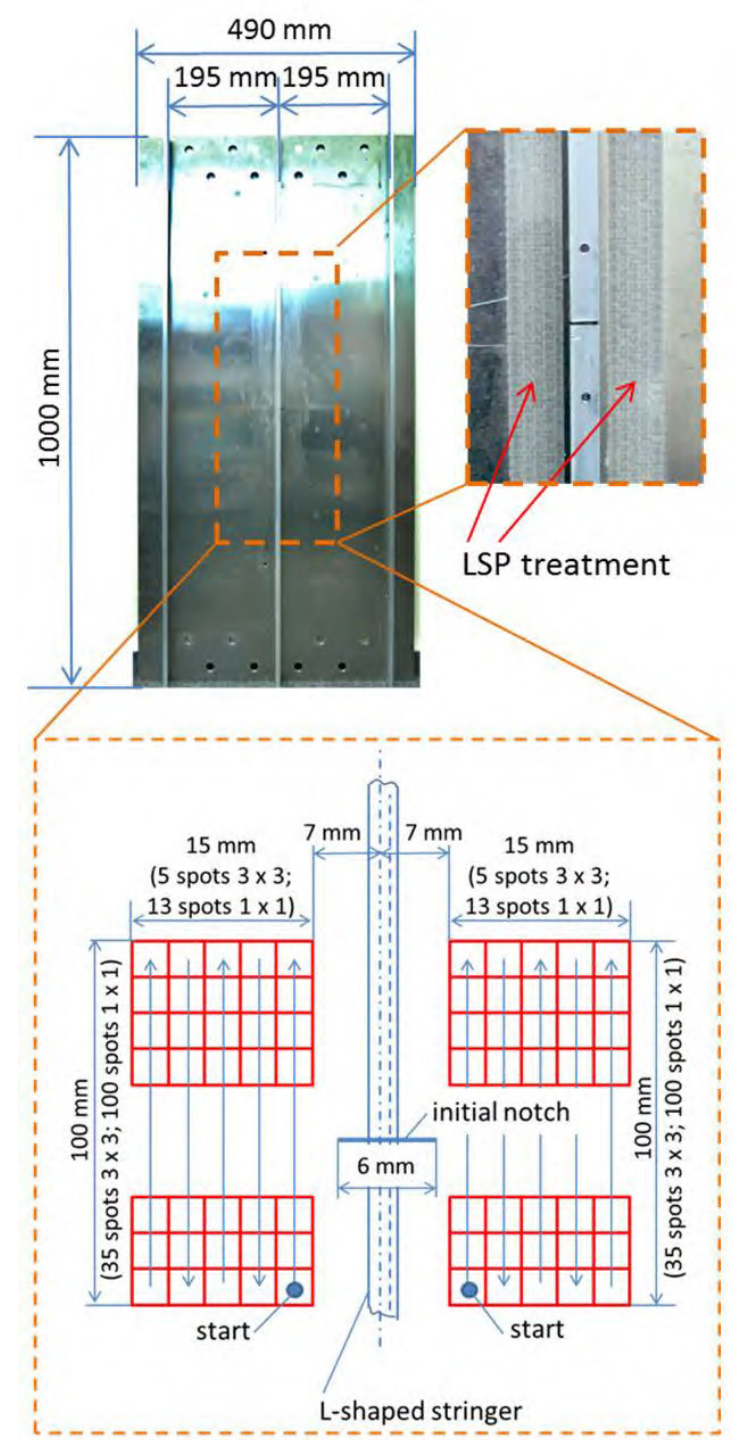

Fig. 3. Photo of the three-stringer-SSFSW-panel with two LSPareas and sketch with the details of LSP-treatments.

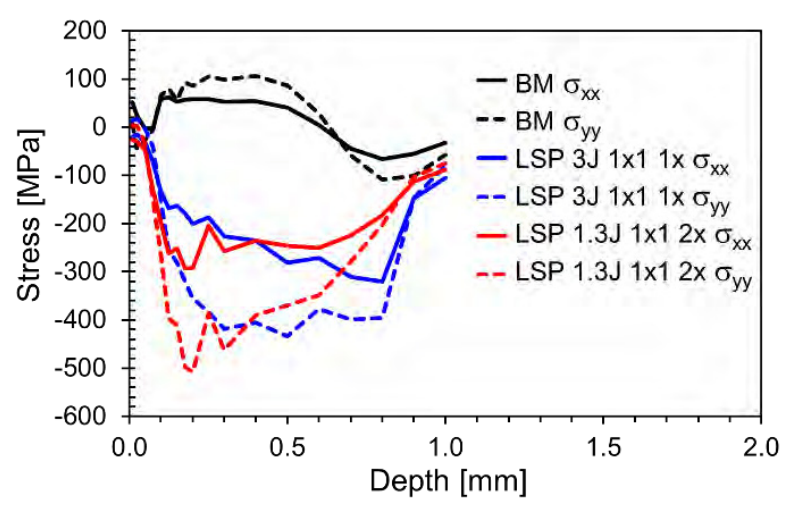

Fig. 4. Residual stress profiles measured with hole drilling method for C(T)50 BM specimen and two LSP-treated specimens. Average curves were calculated from three measurements. In case of LSP-treated specimens, the measurements were performed at three points in the middle of LSP-area.

The LSP-treated specimens show compressive residual stresses also in the core region of the specimens.
The two LSP-treated specimens possess a comparable integral stress area due to the compressive residual stresses. The compressive residual stresses $\sigma_{\mathrm{yy}}$ are significant higher than the one in $\mathrm{x}$-direction $\sigma_{\mathrm{xx}}$. It should be mentioned, that the obtained maximum values of compressive residual stresses of approx. $500 \mathrm{MPa}$ are significantly higher than the yield strength of the material investigated $(370 \mathrm{MPa})$. As the used hole drilling technique overestimates residual stress values close or above the yield strength of the material, as investigated in [13], the real residual stress values should be lower. In case of equibiaxial residual stress profiles a correction methodology based on artificial neural network can be applied [14]. Nevertheless, the used hole drilling technique provides an useable qualitative result. It can be observed, that even in the centre of the specimens, compressive residual stresses are present. The results show, that by the use of the LSP treatment the generation of compressive residual stresses troughthe-thickness of thin sheet material is possible.

\subsection{FCP test on $\mathrm{C}(\mathrm{T})$-specimens}

The specimens used for the FCP test are compact tension $\mathrm{C}(\mathrm{T})$-specimens according to the standard ASTM E64711 with a width $\mathrm{W}=50 \mathrm{~mm}$. All $\mathrm{C}(\mathrm{T}) 50$-specimens were machined with the loading axis parallel to the rolling direction of the sheet material. Initial pre-cracks at $\mathrm{a}_{0}=10 \mathrm{~mm}$ and $\mathrm{a}_{0}=15 \mathrm{~mm}$ were introduced by electro discharge machining.

FCP tests were carried out using a servo-hydraulic machine with a capacity of $25 \mathrm{kN}$. Each specimen set was investigated under the same test conditions, i.e. the same cycle stress, applied load ratio $R_{F}=0.1$, frequency of $10 \mathrm{~Hz}$ and room temperature. All specimens were polished in the expected area where the crack was supposed to grow to be able to observe the crack growth using an optical microscope. The crack growth was recorded automatically using a clip in the crack mouth and a second measurement consisting of periodic tracking of the locations of the crack tip using an optical microscope to magnify the crack. For both methods, the crack growth was recorded by the crack length data as a function of the number of cycles. An incremental second-order polynomial fitting method was used to filter the data in order to reduce the margin of error. A crack opening displacement (COD) clip was mounted on the front side of each $\mathrm{C}(\mathrm{T}) 50$-specimen before the FCP tests. During the FCP tests, the applied load vs. COD curves were obtained.

In Figure 5 the FCP test results are presented. The LSP-treated specimens show a significant higher number of cycles required for propagating the fatigue crack up to the a/W-value of 0.6 (crack length, a divided by the $\mathrm{C}(\mathrm{T}) 50$-specimen width from the pin holes, $\mathrm{W}=50$ $\mathrm{mm}$ ). Figure 5(a) depicts the results of the FCP tests performed for LSP-treated specimens using $1 \mathrm{~mm} \mathrm{x}$ $1 \mathrm{~mm}$ optic. The fatigue life of the LSP-treated specimens LSP 1.3J 1x1 1x increased by a factor of nearly two compared to the BM specimens. Further increase in the fatigue life by a factor of at least nine 
compared to the BM specimens is achieved for the LSPtreated specimens LSP 1.3J 1x1 2x and LSP 3J 1x1 1x. A comparable fatigue life increase can be achieved either by increasing the laser energy from $1.3 \mathrm{~J}$ to $3 \mathrm{~J}$ or by increasing the numbers of overlapping LSP treatments from $1 \mathrm{x}$ to $2 \mathrm{x}$ keeping the laser energy value constant at $1.3 \mathrm{~J}$. The comparable fatigue life increase for the two LSP treatments can be explained in comparable integral stress areas of residual stress profiles for the two LSP treatments (Figure 4). The scatter in the fatigue life is higher for the specimens LSP $3 \mathrm{~J} 1 \mathrm{x} 1 \mathrm{x}$ which might be related to the scatter in the residual stresses induced through the LSP-treatment. The residual stress scatterfatigue life scatter relationship is investigated in details in [15].

Figure 5(b) depicts the FCP test results performed for the LSP-treated specimens using $3 \mathrm{~mm}$ x $3 \mathrm{~mm}$ optic. The fatigue life for the LSP-treated specimen with $3 \mathrm{x}$ overlapping increased by a factor of nearly three compared to the BM specimen. Further fatigue life increase up to a factor of nearly four was obtained for the LSP-treated specimen with $5 \mathrm{x}$ overlapping.

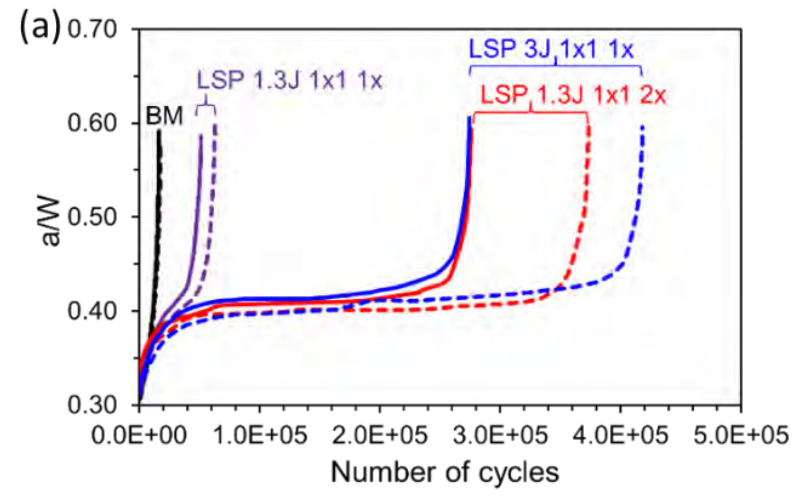

(b)

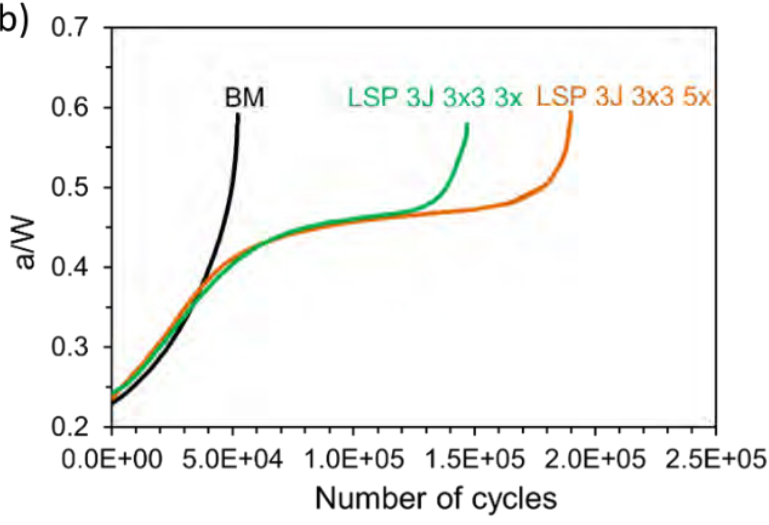

Fig. 5. FCP-test results for (a) $1 \mathrm{~mm} \times 1 \mathrm{~mm}$ optic and (b) $3 \mathrm{~mm} \times 3 \mathrm{~mm}$.

The results of the FCP tests confirmed that significant retardation of fatigue crack propagation can be achieved for the LSP treatments performed using both diffractive optics. The positive effect of LSP can be increased by either increasing the laser energy or increasing the numbers of overlapping LSP treatments.

\subsection{Consideration of LSP-induced residual stresses in the evaluation of FCP behaviour}

To understand the retardation of the FCP in the LSPtreated specimens the applied load vs. crack opening displacement (COD) curves obtained at different crack lengths (a/W-values) were analysed. Throughout the analysed $\mathrm{a} / \mathrm{W}$-region from the beginning of the FCP test $(\mathrm{a} / \mathrm{W}=0.2)$ to the end of the FCP test $(\mathrm{a} / \mathrm{W}=0.6)$, the curves in case of the BM are linear. The curves do not show any noticeable inflection points at the beginning of the test at $\mathrm{a} / \mathrm{W}=0.2 \mathrm{~mm}$ and close to the end of the test at $\mathrm{a} / \mathrm{W}=0.56$ (Figure 6(a)). In contrast to the $\mathrm{BM}$ specimen, the LSP-treated specimens show inflection points in the applied load vs. COD curves (Figure 6(b)). The curves obtained at different crack lengths show different curvatures for the first parts of the curves up to the inflection points. At the beginning of the FCP test, the applied vs. COD curves of the LSP-treated specimen shows a negative curvature (syncline) up to the inflection points. The gradients of the second parts of the curves are comparable to the gradients of the BM curves obtained at the same a/W-values. The lower gradients of the first parts of the curves indicate that tensile residual stresses were present. Tensile residual stresses increase the effective maximum load.

The curves for LSP-treated specimen obtained at $\mathrm{a} / \mathrm{W}$-values in the range between 0.47 and 0.59 show the positive curvature (anticline) in their first parts. The higher gradient of the first part of the curves indicate, that compressive residual stress were present and caused the crack closure that also increased the level of opening load, $\mathrm{F}_{\mathrm{op}}$. Taking into account the effective maximum load at the beginning of the FCP test (region with tensile residual stresses) and the increased values of the opening load in the region with compressive residual stresses, the effective load ratios, $R_{F \text { eff }}$ can be calculated. The proposed methodology for incorporation of tensile and compressive residual stresses in the calculating of effective load ratios is described in details in [16].

The applied (for BM specimen) and effective load ratios for two LSP-treated specimens are presented in Figure 7(a). The crack closure from the compressive residual stress for the LSP-treated specimen increased the level of opening load and therefore reduced the effective load amplitude. In the tensile residual stress regions (at the beginning of the FCP test), the effective load ratio was insignificantly reduced. The $\mathrm{R}_{\mathrm{F}}$-ratio for the $\mathrm{BM}$ specimen remained nearly constant during the FCP test. A similar retardation mechanism has been described also for FCP in laser heating induced residual stresses in [17], with the difference, that there tensile residual stresses are induced in the treated area, surrounded by compressive residual stresses. 

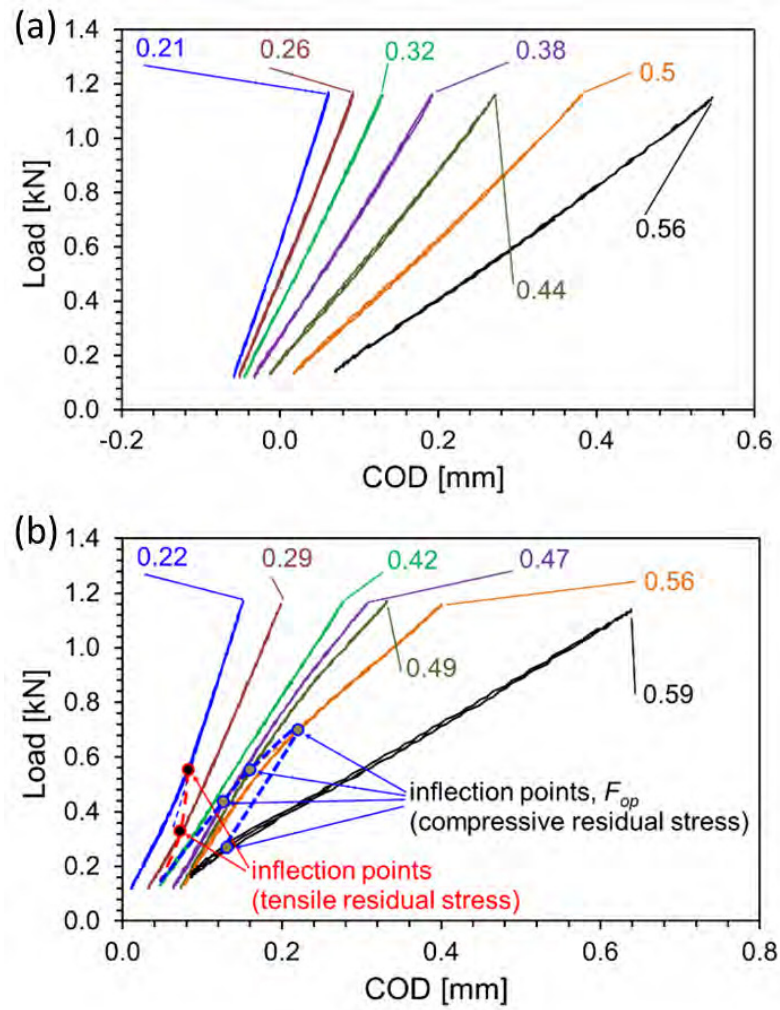

Fig. 6. Load vs. COD curves obtained at different a/W-values for (a) BM specimen (b) LSP-treated specimen (LSP 3J 3x3 $5 \mathrm{x})$.

The FCP rates vs. applied stress intensity factor range, $\Delta \mathrm{K}$, are depicted in Figure $7(\mathrm{~b})$. The $\mathrm{BM}$ specimen shows a typical linear behaviour in the logarithmic coordinates. The calculated $\Delta \mathrm{K}$ values for the LSP treated specimens, considering the applied load levels, show minimum da/dN values at a $\Delta \mathrm{K}$ value of approximately $20 \mathrm{MPa} \sqrt{\mathrm{m}}$. By considering the effect of tensile and compressive residual stresses on the effective load range for the calculation of the stress intensity factor range, i.e., the so-called effective stress intensity factor range, $\Delta \mathrm{K}_{\text {eff }}$ curves for the LSP-treated specimens are close to the curve of the BM specimen. It is evident that the applied corrections for calculating $\Delta \mathrm{K}_{\text {eff }}$ are reasonable and consider the effects of the tensile/compressive residual stresses induced by the LSP treatment.

\subsection{FCP test on $M(T)$-specimens}

Constant amplitude FCP tests were carried out at load ratio, $\mathrm{R}_{\mathrm{F}}$ of 0.1 , using a servo-hydraulic machine at a frequency $\mathrm{f} \leq 5 \mathrm{~Hz}$ in compliance with the standard ASTM E 647. It should be mentioned that the ASTM standard assumes homogeneous material properties; a condition, which may not necessarily be fulfilled for friction stir welded structures.
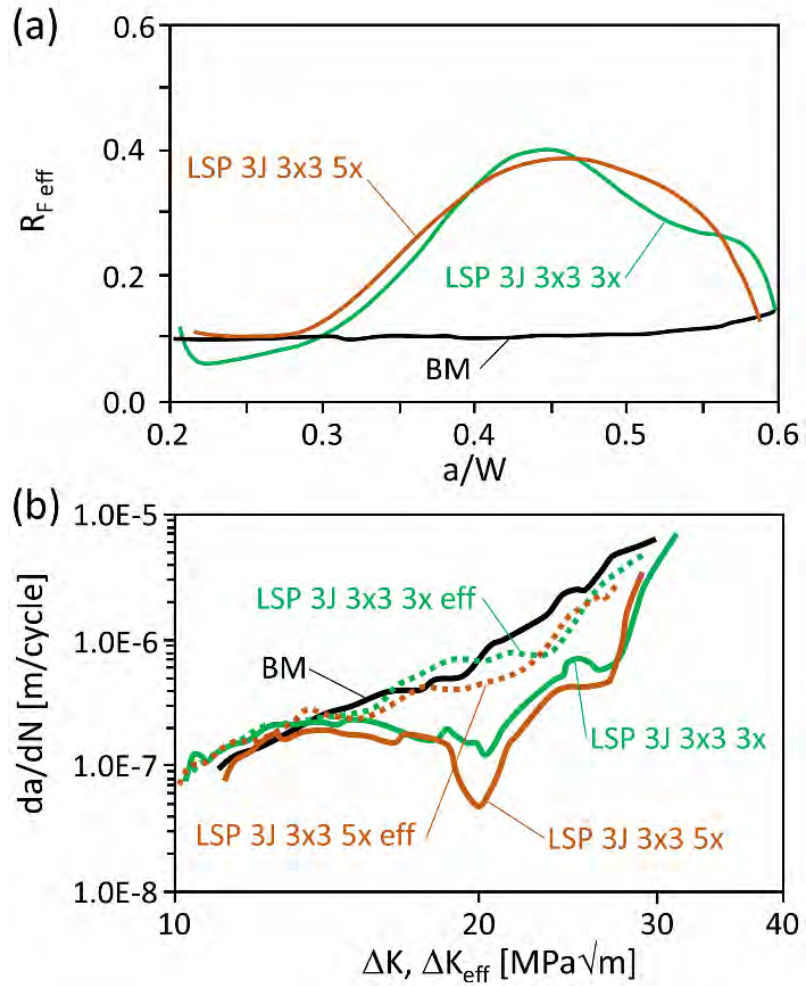

Fig. 7. Correction of effective values under consideration of the LSP-induced residual stresses. (a) $\mathrm{R}_{\mathrm{F}}$ eff vs. a/W and (b) da/dN vs. $\Delta \mathrm{K}$ and $\Delta \mathrm{K}_{\text {eff. }}$

The stringer specimens were notched using an electrodischarge technique. A notch of $2 \mathrm{a}_{0}=6 \mathrm{~mm}$ was placed in the centre of the panel (the stringer in the middle of the panel was cut, Figure 3). The crack length was measured optically using a travelling microscope.

The results of the FCP test for three-stringer panels are shown in Figure 8. A considerable effect of LSPtreatment in the FCP behaviour was observed. In case of the stationary shoulder friction stir welded specimen with two LSP-treated areas using the LSP process parameter set $2(5 \mathrm{~J} 3 \times 33 \mathrm{x}$, Table 1$)$ the fatigue life is increased by a factor of more than two compared to the stationary shoulder friction stir welded specimen without LSP treatment. The LSP process parameter set 1 (5J $1 \mathrm{x} 1$ $3 x$, Table 1) led to the fatigue life increase by a factor of more than four. The obtained results indicate that LSP is an effective process for extension of the fatigue life of aircraft structural components. It can be successfully implemented on thin-walled airframe structures to increase their resistance against fatigue crack propagation. 


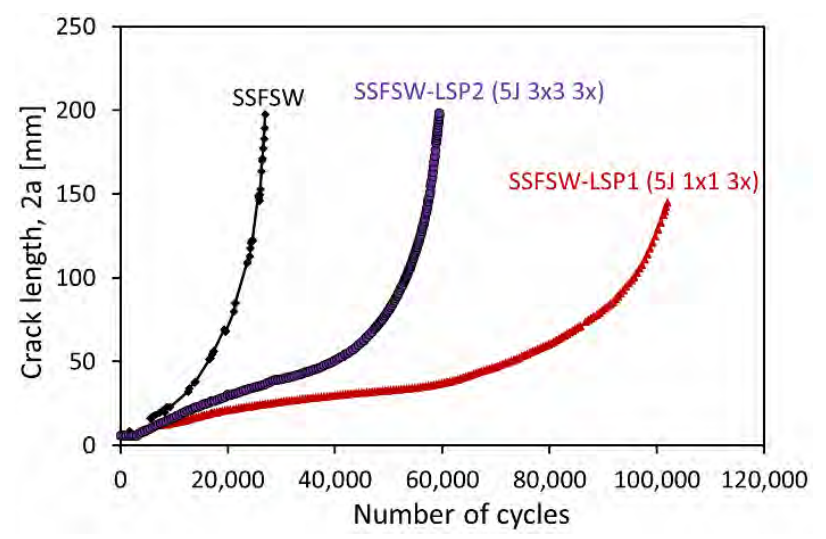

Fig. 8. Fatigue crack propagation test results of stationary shoulder friction stir welded 3-stringer panels with LSP treatments.

\section{Conclusions}

Based on the obtained results the following conclusions can be drawn:

1. LSP is an effective process for introducing high and deep compressive residual stresses in thin AA2024 sheets.

2. A significant retardation of the FCP through the presence of compressive residual stresses induced by the LSP treatment was observed.

3. A crack closure effect in the FCP tests was observed in specimens with the LSP treatment, which is caused by the presence of high compressive residual stresses.

4. The efficiency of the LSP process has been demonstrated on sub-component level resulting in an increase of $200-400 \%$ in fatigue lifetime.

Overall, LSP can be considered as a potential tool for the surface treatment of Al-structures in which a nondestructive inspection can detect cracks. The effects of the LSP treatment are the arrest of cracks and deceleration of the FCP.

This work was carried out within the frame of the LISA project, which was supported by the Light-weight materials Assessment, Computing and Engineering Centre (ACE) of the division Materials Mechanics of the Helmholtz-Zentrum Geeesthacht. The authors also thank the following project members for their valuable work and support: H. Tek and K. Erdmann (mechanical testing), L. Moura (using the hole drilling system) and F. Dorn (specimen preparation).

\section{References}

1. O. Hatamleh, M. Hill, S. Forth, D. Garcia, Mater. Sci. Eng. A 519, 61 (2009)

2. S. Keller, S. Chupakhin, P. Staron, E. Maawad, N. Kashaev, B. Klusemann, J. Mater. Proc. Tech. 255, 294 (2018)
3. L. Berthe, R. Fabbro, P. Peyre, E. Bartnicki, Eur. Phys. J. Appl. Phys. 3, 215 (1998)

4. L. Berthe, R. Fabbro, P. Peyre, E. Bartnicki, J. Appl. Phys. 85, 7552 (1999)

5. C. Correa, L. Ruiz de Lara, M. Diaz, J. A. Porro, A. Garcia-Beltran, J. L. Ocaña, Int. J. Fatigue 70, 196 (2015)

6. Y. Tan, G. Wu, J. M. Yang, T. Pan, Fatigue Fract. Eng. Mater. Struct. 27(8), 649 (2004)

7. O. Hatamleh, J. Lyons, R. Forman, Int. J. Fatigue 29(3), 421 (2007)

8. O. Hatamleh, Int. J. Fatigue 31(5), 974 (2009)

9. E. Hombergsmeier, V. Holzinger, U. C. Heckenberger, Adv. Mater. Res. 891-892, 986 (2014)

10. Z. Bergant, U. Trdan, J. Grum, Int. J. Fatigue 87, 444 (2016)

11. A. Barbini, J. Carstensen, J. F. dos Santos, J. Mater. Sci. Tech. 34(1), 119 (2018)

12. M. Steinzig, E. Ponslet, Exp. Tech. 27(3), 43 (2003)

13. S. Chupakhin, N. Kashaev, N. Huber, J. Strain Anal. Eng. Des. 51(8), 572 (2016)

14. S. Chupakhin, N. Kashaev, B. Klusemann, N. Huber, J. Strain Anal. Eng. Des. 52(3), 137 (2017)

15. S. Chupakhin, B. Klusemann, N. Huber, N. Kashaev Int. J. Adv. Manuf. Tech., submitted

16. N. Kashaev, V. Ventzke, M. Horstmann, S. Chupakhin, S. Riekehr, R. Falck, E. Maawad, N. Schell, N. Huber, Int. J. Fatigue 98, 223 (2017)

17. D. Schnubel, N. Huber N, Eng. Fract. Mech. 84, 15 (2012) 